\title{
THE LAMININ 511/521 BINDING SITE ON THE LUTHERAN BLOOD GROUP GLYCOPROTEIN IS LOCATED AT THE FLEXIBLE JUNCTION OF Ig DOMAINS 2 AND 3.
}

\author{
Tosti J. Mankelow ${ }^{1,7}$, Nicholas Burton ${ }^{2,7}$, Fanney O. Stefansdottir ${ }^{1}$, Frances A. Spring ${ }^{1}$, \\ Stephen F. Parsons ${ }^{1}$, Jan S. Pedersen ${ }^{3}$, Cristiano L.P. Oliveira ${ }^{3}$, Donna Lammie ${ }^{4}$, \\ Timothy Wess ${ }^{4}$, Narla Mohandas ${ }^{5}$, Joel A. Chasis ${ }^{6}$, R. Leo Brady ${ }^{2}$ and David J. Anstee ${ }^{1}$. \\ ${ }^{1}$ Bristol Institute for Transfusion Sciences, National Blood Service, Bristol, UK. \\ ${ }^{2}$ Dept of Biochemistry, University of Bristol, Bristol, UK. \\ ${ }^{3}$ Department of Chemistry, University of Aarhus, Aarhus, Denmark \\ ${ }^{4}$ School of Optometry and Vision Sciences, Cardiff University, Cardiff, UK. \\ ${ }^{5}$ New York Blood Center, New York, NY 10021, USA. \\ ${ }^{6}$ University of California, Lawrence Berkeley National Laboratory, Berkeley, CA 94720, \\ USA \\ ${ }^{7}$ These authors contributed equally to this work.
}

Short title: Molecular basis of Lutheran binding to Laminin.

\section{Scientific category: Red Cells}

Presented in part as an abstract to the $48^{\text {th }}$ Annual meeting of the American Society of Hematology, Orlando FL December 9-12 2006

Address correspondence to:

R. Leo Brady, Department of Biochemistry, University of Bristol, Bristol BS8 1TD U.K.; Tel. +44(0)117 117331 2150; Fax +44(0)117 117331 2168; Email: L.Brady@bris.ac.uk.

Tosti J Mankelow, BITS, Southmead Road, Bristol, BS10 5ND, UK; Tel +44(0)1179912123; Fax +44(0)1179591660, Email: tosti.mankelow@nbs.nhs.uk

Keywords: Extracellular matrix / Lutheran glycoprotein / Laminin / sickle cell disease / Xray crystallography.

Abbreviations used: ECM, Extracellular matrix; Lu gp, Lutheran glycoprotein; Lu gpFc, Lutheran glycoprotein Fc fusion protein; Ln, Laminin; Ln511/521, Laminin 511/521; LG, Laminin type $\mathrm{G}$ domain; IgSF, immunoglobulin superfamily SAXS; small-angle X-ray scattering.

\section{Abstract Word Count 185 \\ Total Word Count:4960}




\begin{abstract}
The Lutheran blood group glycoprotein, first discovered on erythrocytes, is widely expressed in human tissues. It is a ligand for the $\alpha 5$ subunit of Laminin 511/521, an extracellular matrix protein. This interaction may contribute to vasocclusive events that are an important cause of morbidity in sickle cell disease. Using X-ray crystallography, small angle X-ray scattering and site directed mutagenesis we show that the extracellular region of Lutheran forms an extended structure with a distinctive bend between the second and third immunoglobulin-like domains. The linker between domains 2 and 3 appears to be flexible and is a critical determinant in maintaining an overall conformation for Lutheran that is capable of binding to Laminin. Mutagenesis studies indicate that Asp312 of Lutheran and the surrounding cluster of negatively charged residues in this linker region form the Laminin binding site. Unusually, receptor binding is therefore not a function of the domains expected to be furthermost from the plasma membrane. These studies imply that structural flexibility of Lutheran may be essential for its interaction with Laminin and present a novel opportunity for the development of therapeutics for sickle cell disease.
\end{abstract}

\title{
Introduction
}

The Lutheran glycoprotein ( $\mathrm{Lu} \mathrm{gp}$ ) cellular adhesion molecule is widely expressed in human tissues ${ }^{1}$ and is known for carrying antigens of the Lutheran blood group system. On erythrocytes Lu gp is expressed as two isoforms of 78 and $85 \mathrm{kDa}^{2}$. Both share a common extracellular portion which has previously been predicted to comprise 5 immunoglobulin superfamily (IgSF) domains ${ }^{1}$. The $78 \mathrm{kDa}$ isoform (also known as $\mathrm{BCAM}^{3}$ or $\mathrm{Lu}[\mathrm{v} 13]^{4}$ ) results from alternative splicing and lacks $40 \mathrm{C}$ terminal amino-acids within the cytoplasmic domain which contain an $\mathrm{SH} 3$ binding motif, a dileucine motif responsible for basolateral targeting ${ }^{5}$ and five potential phosphorylation sites ${ }^{1}$.

Lu gp binds specifically and with high affinity to the extracellular matrix (ECM) protein Laminin (Ln) containing the $\alpha 5$ subunit $^{6-9}$ (Laminin 511 and Laminin 521 (Ln511/521) (numbering as in ${ }^{10}$ ). This interaction plays a direct role in the pathophysiology of sickle cell disease by mediating adhesion of sickle cells, via Lu gp, to exposed Ln511/521 of inflamed or damaged vascular endothelium ${ }^{9,11,12}$. Recent studies have shown that higher than normal intracellular levels of cAMP in sickle erythrocytes influence a protein kinase A mediated or Rap1-mediated signalling pathway resulting in increased adhesion of sickle cells to the basement membrane glycoproteins Ln511/521 ${ }^{13,14}$. Furthermore, phosphorylation of the $85 \mathrm{kDa} \mathrm{Lu}$ gp at S621 in epinephrine stimulated K562 cells alters adhesion to Ln511/521 ${ }^{15}$.

The Ln binding activity of Lu gp is a property of the amino terminal region of Lu gp, and has been localised to a region predicted to form the first three IgSF domains (D1D2D3) ${ }^{6,16}$. The complementary binding site on $\mathrm{Ln}$ is located within a large carboxyl-terminal globular domain of the $\alpha 5$ subunit, known to comprise five Laminin-type G (LG) modules, LG1 to LG5 ${ }^{17,18}$. These modules, present at the carboxy termini of all $\mathrm{Ln} \alpha$ chains, have also been shown to regulate binding to at least 6 integrins ${ }^{18-20}$ in addition to $\alpha$-dystroglycan and heparin ${ }^{21-23}$. Binding to the latter two ligands results from positively charged residues on $\mathrm{Ln}$ and regions of negative charge (acidic sugar residues) on heparin and $\alpha$-dystroglycan ${ }^{24,25}$. 
Here we use a multidisciplinary approach to explore the molecular basis of the interaction between Lu gp and Ln511/521. We describe the elucidation of a structure for the Ln binding portion of the Lu gp molecule. This structure comprises a high resolution crystal structure for domains 1 and 2 (D1D2) to which has been added a predicted model for domain 3 (D3) by fitting to a molecular envelope calculated from small-angle X-ray scattering (SAXS) data. The location of these domains within the overall extracellular form of $\mathrm{Lu}$ is also demonstrated by SAXS. Secondly, sitedirected mutagenesis has been used to examine residues suspected to be involved in the interaction with $\mathrm{Ln}$. This led to the identification of amino-acid residues comprising the Ln511/521 binding site on $\mathrm{Lu}$ gp. An unexpected finding is that, unlike most cell-cell interactions that characteristically result from the formation of cell adhesion pairs between the membrane-distal domains of cell adhesion molecules (e.g. CD2:CD58 ${ }^{26}$ and CD2:CD48 ${ }^{27}$ ), Lu gp uses a more membrane-proximal interdomain junction region to form a critical part of its Ln binding site.

\section{Materials and Methods}

\section{Synthesis, purification and crystallisation of $\mathrm{Lu} g \mathrm{p}$}

The extracellular domains of human $\mathrm{Lu}$ gp were expressed as Fc fusion proteins in NS0 cells using the procedures as described ${ }^{28}$. Residues 1-330 (D1D2D3), residues 1515 (Lu gp), were included in the expressed proteins, immediately followed at the Cterminus by the Tobacco Etch Virus protease (TEV) cleavage site VDENLYFQG and human IgG Fc immunoglobulin fragment. Secreted fusion proteins were purified from cell supernatant using Protein A Sepharose and the Fc fragment was liberated by digestion with recombinant TEV (Invitrogen, Paisley, UK) and removed on Protein A Sepharose.

The D1D2 fragment was liberated by chymotrypsin digestion of the purified D1D2D3, using a 1:100 enzyme:Lu ratio at $\mathrm{pH} 7.4$ for 18 hours at $18^{\circ} \mathrm{C}$. Chymotrypsin was removed with a benzamidine column (Amersham Biosciences) prior to a final gel filtration purification step (HiLoad 16/60, Superdex 75 prep grade, Amersham Biosciences).

For crystallisation trials proteins were concentrated to $8 \mathrm{mg} / \mathrm{ml}$ in $20 \mathrm{mM}$ HEPES pH 7 buffer. Diffraction quality hexagonal crystals were grown from a mother liquor containing $18 \%$ (w/v) PEG4000, 0.1M sodium citrate (pH5.6), 0.2M ammonium acetate. A second monoclinic crystal form was obtained from $12 \%$ (w/v) PEG20000, 0.1M MES ( $\mathrm{pH} 6.4$ ), 6\% (w/v) hexane-1,2-diol. Heavy atom derivatives of crystals were prepared by soaking in well solutions supplemented with either $10 \mathrm{mM}$ potassium tetrachloro platinate (II) for $24 \mathrm{~h}$ or $100 \mathrm{mM}$ potassium dicyanoaurate (I) for 72h. Diffraction data were collected at the Daresbury SRS synchrotron on beamlines 14.1 and 10.1 (see Table 1). Crystals of the monoclinic form (one molecule per asymmetric unit) generally produced higher quality diffraction data and were used for the experimental phase determination. Heavy atom sites were located with SHELXD ${ }^{29}$ and refined with $M L P H A R E^{30}$. Density modification was performed using $D M^{30}$ and $A R P / w A R P^{31}$. The model was refined against the native amplitudes and experimental phases using REFMAC $5^{30}$. The hexagonal crystal form was solved by molecular replacement using $P H A S E R^{32}$ using separate domains from the monoclinic structure 
as search models. The structure was initially refined with $C N S^{33}$, using a simulated annealing protocol, then fully refined with REFMAC5. The validity of the structures was assessed with MOLPROBITY ${ }^{34}$. Refinement statistics are summarised in Table 1.

\section{Lu gp D3 homology model}

Sequence comparisons indicated that D3 was most similar to the $\operatorname{Ig} 3$ domain of perlecan (PDB ID 1gl4, chain $\mathrm{B}^{35}$ ), a known I-set IgSF domain, and this was used as the structural template for the model of D3. Sequences were aligned with ClustalW and adjusted manually; secondary structure was predicted with the Jpred ${ }^{36,37}$ and SAMT0 $2^{38}$ servers. The sequence alignment and secondary structure predictions were used as input for Modeller ${ }^{39}$ to generate the three-dimensional model.

\section{Small-Angle X-ray scattering analysis}

Full SAXs methods can be found as Supplementary Data 1. Briefly, SAXS data of D1D2D3 were collected on beamline X33 at the European Molecular Biology Laboratory (EMBL) of the Deutsches Elektronen Synchrotron (DESY) using a wavelength of $\lambda=0.15 \mathrm{~nm}$, covering a scattering range of $0.16 \mathrm{~nm}^{-1}<\mathrm{q}<4.85 \mathrm{~nm}^{-1}$, where $\mathrm{q}=4 \pi \sin \theta / \lambda ; 2 \theta$ is the scattering vector. Sample concentrations were $4.375 \mathrm{mg} / \mathrm{ml}$, $8.75 \mathrm{mg} / \mathrm{ml}$ and $17.5 \mathrm{mg} / \mathrm{ml}$; samples were supplemented with $1 \mathrm{mM}$ dithiothreitol and exposed for $60 \mathrm{~s}$, scattering data from the buffer solution was also collected. The scattering images were integrated to one-dimensional linear profiles using in-house software at station X33. Scattering data were processed with the ATSAS2.1 software suite as previously described ${ }^{40}$.

SAXS data for the entire extracellular portion of Lu (D1-D5) were collected using the modified version of a NanoSTAR (Bruker AXS, Karlsruhe) at the University of Aarhus, see ${ }^{41}$ for details. The sample concentration was $15 \mathrm{mg} / \mathrm{ml}$ and the scattering range was $0.085<\mathrm{q}<3.5 \mathrm{~nm}^{-1}$. The two-dimensional data were azimuthally averaged to one-dimensional linear profiles using Bruker SAXS software. Data was processed as above, except that buffer scattering subtraction and transformation to absolute units using the scattering of water as a standard was performed with in-house software at the University of Aarhus.

\section{Preparation of mutant and native Lu gp Fc fusion proteins (Lu gpFc)}

Point mutations were inserted into human Lu gp cDNA clones ${ }^{42}$ encoding the five extracellular domains in pIg vector by PCR amplification as described ${ }^{43}$. Mutant clones were confirmed by DNA sequence analysis. Native and mutant Lu gpFc and Muc-18 Fc (a gift from Dr Simmons (Glaxo SmithKline, Harlow, UK) were expressed in COS-7 cells, purified using protein A-Sepharose and quantified as described $^{43}$.

\section{Lu gp binding Ln511/521 ELISA}

Washes and protein dilutions were performed in phosphate-buffered saline with $0.2 \%$ bovine serum albumin (assay buffer). All protein dilutions were added in $50 \mu \mathrm{l}$ and incubations were at $37^{\circ} \mathrm{C}$ with shaking for one hour unless stated otherwise. Immulon496 well plates (Dynes Technologies, West Sussex, UK) were coated with 
$0.25 \mu \mathrm{g} /$ well goat-anti-human-Fc (Jackson ImmunoResearch, Cambridgeshire, UK) in $0.1 \mathrm{M}$ bicarbonate buffer, $\mathrm{pH} 9.6$ for 24 hours at $4^{\circ} \mathrm{C}$. After three washes 5, 0.5, 0.05 and $0.005 \mathrm{nM}$ native or mutated $\mathrm{Lu} \mathrm{gpFc}$ was added and the plate incubated. After one wash the plate was blocked for 30 minutes at room temperature in assay buffer containing 5\% human $\mathrm{AB}$ serum followed by one wash. Ln511/521 (Chemicon, Hampshire, UK) at $5 \mathrm{nM}$ was added and the plate incubated. After three washes a 1 in 100 dilution of rabbit anti-laminin (Sigma, Dorset, UK) was added, the plate incubated and after three washes a 1 in 1000 dilution of horse radish peroxidase linked swine anti-rabbit (DAKO, Cambridgeshire, UK) was added, incubated and washed a further three times. The plate was developed using 3,3',5,5'Tetramethylbenzidine and $3 \% \mathrm{H}_{2} \mathrm{O}_{2}$ in $0.1 \mathrm{M}$ acetate/citrate buffer $\mathrm{pH} 6$, stopped with $2 \mathrm{M} \mathrm{H}_{2} \mathrm{SO}_{4}$ and read at $450 \mathrm{~nm}$. The ELISA was controlled by coating wells with $5 \mathrm{nM}$ Ln511/521 and by addition of 5nM Ln511/521 to captured Muc18 Fc.

\section{Surface Plasmon Resonance Assays}

All assays were performed at $25^{\circ} \mathrm{C}$ using a Biacore $\mathrm{X}$, a CM5 chip with protein A immobilised on its surface and a flow rate of $30 \mu \mathrm{l}$ per minute. Running buffer was phosphate buffered saline $\mathrm{pH} 7.4$ containing $0.05 \%$ Tween 20 and regeneration buffer was $0.1 \mathrm{M}$ glycine $\mathrm{pH} 2$. Native or mutant $\mathrm{Lu}$ gpFc was captured onto the chip until a change of 40 response units was observed $(0.25 \mathrm{pm})$. Ln511/521 was added in a $100 \mu \mathrm{l}$ injection of $10 \mathrm{nM}(1 \mathrm{pm})$.

\section{Results}

\section{Crystal structure of Lu gp D1D2}

Extensive attempts to crystallise fragments of $\mathrm{Lu}$ gp comprising either all three $\mathrm{N}$ terminal domains (residues 1-330) or the entire extracellular region were unsuccessful, consistent with innate molecular flexibility in Lu gp. Instead, a stable fragment of $\mathrm{Lu}$ gp consisting of domains 1 and 2 (D1D2) was produced by chymotryptic digestion of the three-domain construct. This fragment was purified and crystallised in two crystal forms (Table 1). In the refined crystal structures the asymmetric unit of the monoclinic form contains one molecule, whereas there are two molecules in the hexagonal asymmetric unit. Together these provide three separate views of Lu gp D1D2. Coordinates and structure factors for the D1D2 crystal structures are available from the Protein Data Base (accession codes 2PET (monoclinic form) and 2PF6 (hexagonal form)).

The crystal structures show the amino terminal portion of Lu gp consists of two IgSF domains (Figure 1) which together form a monomeric straight rod approximately $85 \AA$ long and $25 \AA$ wide. There is limited flexibility between the two domains, the relative positions of which are seen to vary by up to $12^{\circ}$ when the three non-identical molecules from the two crystal forms are compared (Figure 1b). Domain 1 (D1) is formed from residues 1-111 and is, as predicted, a member of the V-set of immunoglobulin domains (Supplementary Data 2). It contains the conserved disulphide bond between strands $\mathrm{B}$ and $\mathrm{F}$, each of the $\mathrm{B} / \mathrm{C}, \mathrm{C}$ '/C" and F/G loops - the equivalent of complementarity determining loops in the antibody $\mathrm{V}$-domains - are relatively short. The $\mathrm{C} / \mathrm{C}$ ' loop projects away from the body of the domain and appears to be primarily held in this orientation by a salt bridge formed between Arg44 
and Glu105. The base of the domain is intimately associated with domain 2 (D2). The domains are linked by a short run of hydrophobic amino-acids (112Val-Phe-Ala114) which are buried within the interface. Unexpectedly D2 (residues 115-229) lacks A', $\mathrm{C}^{\prime}$ and $\mathrm{C}^{\prime \prime}$ strands ruling out its original sequence-based classification as a V-set domain (Supplementary Data 2). Despite the increased length of the polypeptide chain in this domain it is most like a C1-set domain, unusual outside of immune system proteins. The additional residues are incorporated primarily within extended A/B, C/D and E/F loops, all of which are at the base of the domain. One notable feature is the presence of a short helical segment within the E/F loop. All of these features lead to an extended surface at the C-terminal end of the domain, which lies adjacent to the interface with D3.

The 18 identified antigens of the Lutheran blood group system are predominantly associated with single-nucleotide polymorphisms resulting in single amino-acid changes within Lu gp ${ }^{44}$. A study of 11 of these antigens revealed that in 7 cases these changes could be located to residues in $\mathrm{D} 1$ or $\mathrm{D} 2^{44}$, the sites of which may now be visualised (Figure 1c). The prevalence of these changes in the two amino-terminal domains is consistent with their ready exposure at the cell surface, implying that they may lie furthermost from the membrane. These allelic changes appear to be distributed across all of the available faces of D1D2 and all occur at surface exposed regions including both loop and sheet locations. In all cases the observed amino-acid changes are not expected to be deleterious for the overall Lu gp structure.

\section{Construction of an homology model for D3}

Chymotryptic digestion of D1D2D3 consistently resulted in proteolysis of D3, preventing an experimental determination of its structure. We therefore constructed a molecular model of D3 (residues 236-324), based on its sequence homology with known I1-set domains. Note that this differs from the original classification of D3 as a C2-set domain ${ }^{1}$. The two single-point mutations (S244 and T271) associated with D3 inherited blood group antigens (LU6/LU9 and LU20) were both found to be located on the surface of the final model, an assumption not made throughout the modeling process.

\section{SAXS analysis of Lu gp}

In order to delineate the placement of D3 with respect to D1D2 we performed a SAXS analysis of the D1D2D3 construct. Two methods were used to independently derive an overall conformation of D1D2D3. Firstly, the scattering data (Figure 2a) were fitted with ab initio bead models using two separate programs, DAMMIN ${ }^{45}$ and $\mathrm{GASBOR}^{46}$. In each case chi values of $\approx 1.9$ were obtained, and both methods generated very similar hockey-stick shapes (Figure $2 b$ ). The chi value is a measure of the discrepancy between the experimental data and the theoretical scattering generated by the model, a good fit should return a value $<3$ (with absolute equivalence $=1$ ). Secondly, the crystal structures of Lu gpD1D2 and the model of D3 were fitted as separate rigid bodies to the scattering data using the software SASREF ${ }^{47}$. The resulting chi values ranged from 1.7-1.9. All three crystal structures of D1D2 gave similar results. When superimposed the individual fits show very similar gross conformations with a significant bend angle between domains 2 and 3 (Figure 2c), although the exact orientation of D3 with respect to D2 is insufficiently defined to 
assign a single unique conformation. Similarly, the conformation of the D2-D3 linker peptide is not distinguished in this analysis.

A similar SAXS analysis was also performed on the overall Lu gp (D1-D5) construct. It is evident from the calculated envelopes and shapes that Lu gp forms an extended structure with a distinctive bend to one side of the mid-region (Figure 2d). The derived D1D2 and D1D2D3 structures overlay well at one end of this shape (Figure 2e). Domains 4 and 5 are also expected to adopt IgSF fold, however, due to limited experimental evidence we feel it would be too speculative to include them in our model. Nonetheless, their approximate placement relative to D1D2D3 is evident.

\section{Mutagenesis of acidic residues on D2 and D3 diminishes Ln511/521 binding}

Using full-length $\mathrm{Lu} \mathrm{gp}$ in an ELISA we found that the Lu gp-Ln511/521 interaction is $\mathrm{pH}$ dependent, occurring only in the range between $\mathrm{pH} 5$ and 10. We also confirmed the interaction is inhibited in the presence of high salt $(1 \mathrm{M} \mathrm{NaCl})^{17}$ (data not shown). The dependence on $\mathrm{pH}$ and salt concentration is consistent with charged or polar interactions regulating the binding of the two molecules. There are known areas of positively charged amino-acids on LG domains so we hypothesised that negatively charged residues on $\mathrm{Lu}$ gp would be responsible for Ln binding. This is consistent with the observations that interactions between positively charged residues on Ln and negative charges on both heparin and $\alpha$-dystroglycan provide the basis for these molecular interactions ${ }^{24,25}$. Analysis of an homology model of Lu gp initially allowed us to target surface-exposed clusters of aspartic and glutamic acid residues for mutation; the precise locations of acidic residues on D2 were subsequently demonstrated by the crystal structures. The majority of residues selected are conserved or identical in the mouse Lu gp homologue. Each mutant $\mathrm{Lu}$ gp was detected by Western blotting with monoclonal anti-Lu (BRIC 221 and BRIC 224) and an anti Fc antibody (Supplementary Data 3). Since the epitopes for BRIC 221 and 224 are conformationally dependent and are destroyed in reducing conditions, these results show none of the mutations markedly altered the structure of $\mathrm{Lu} \mathrm{gpFc}$.

The Ln511/521 binding properties of the thirteen mutant Lu proteins were examined by an ELISA using four Lu gp coating concentrations. Over the complete range of Lu gpFc concentrations the $\mathrm{D} 312 \mathrm{~A}$ mutation caused a severe reduction in Ln511/521 binding, E309A and D310A showed a marked reduction, whereas E132A/D133A, D198A/D199A, E269A, D280A and D316A caused only a slight decrease in binding (Figure 3a (Supplementary Data 4). At $0.05 \mathrm{nM}$ the native $\mathrm{Lu}$ gp was exposed to saturating amounts of Ln511/521 so this concentration was used to determine the different levels of adhesion to Ln511/521 of the various Lu gp mutants (Figure 3b (Supplementary Data 4). All other mutant proteins had the same or similar levels of binding to Ln511/521 as that obtained with native Lu gpFc (Figure 3b).

The mutant proteins were also assayed for Ln511/521 binding using a Biacore X (Figures $3 \mathrm{c}$ and $\mathrm{d}$ ) and sensorgrams showed the effect caused by each mutation is similar to that observed by ELISA (Figures 3a and b). The Biacore assays indicate that mutations affecting Ln511/521 binding slow the rate at which Ln511/521 binds to $\mathrm{Lu}$ gpFc whereas the rate at which Ln511/521 dissociates is not affected (Figure 3c). Compared to our earlier study ${ }^{6}$ the rate of dissociation of $\mathrm{Lu}$ gpFc and Ln511/521 is somewhat slower. In the previous published study ${ }^{6}$ an Iasys optical biosensor and a 
different source of Ln511/521 was used making direct comparisons between the two studies difficult. Association and dissociation of Lu gp and the Ln511/521 used in this study was measured on the BiacoreX using Ln511/521 injections at 50nM, 20nM, $10 \mathrm{nM}, 5 \mathrm{nM}$ and $2 \mathrm{nM}$ and the calculated $\mathrm{K}_{\mathrm{D}}$ was $7.2 \mathrm{nM}$ which is comparable to previously reported values $\left(7.9 \mathrm{nM}^{6}\right.$ and $\left.10.8 \mathrm{nM}^{16}\right)$. It was not possible to obtain a set of binding curves to calculate $K_{D}$ for the mutant forms of Lu gp that showed a reduction in Ln binding because of the constraints of the limited availability and solubility of Ln511/521.

The results show E132A/D133A, D198A/D199A, E269A, D316A and to a much greater extent E309A, D310A and D312A, inhibit Ln511/521 binding to Lu gp. These residues cluster within the $\mathrm{A} / \mathrm{B}$ and $\mathrm{E} / \mathrm{F}$ loops at the base of $\mathrm{D} 2$ and $\mathrm{B} / \mathrm{C}$ and $\mathrm{F} / \mathrm{G}$ loops at the top of D3. The location and importance of each amino-acid is depicted in Figure 4.

\section{Mutagenesis of the D2-D3 linker affects Ln511/521 binding}

The results of site-directed mutagenesis described above are consistent with previous studies which used domain-deletion mutants of Lu gp to show that the binding site for Ln511/521 is within the first three domains ${ }^{6,16}$. Despite containing key residues involved in binding Ln511/521 Lu gp proteins containing D2 without D3, and more significantly, D3 without D2 were unable to support binding of Ln511/521 ${ }^{6,16}$. The observation that both D2 and D3 are required for Ln511/521 binding raises the question of the importance of the linker or hinge sequence between D2 and D3 in defining the structure of $\mathrm{Lu}$ gp. We constructed two $\mathrm{Lu}$ gpFc mutants in which residues in the hinge were replaced with a proline (T233P and $\mathrm{H} 235 \mathrm{P})$ and a third mutant that had three residues removed from the hinge ( $\triangle 233-235)$ (Figure 5a). Western blotting with BRIC 221 and 224 confirmed these molecules were folded correctly (Supplementary Data 3). Ln511/521 binding by mutant T233P was markedly reduced and that of $\mathrm{H} 235 \mathrm{P}$ and $\Delta 233-235$ was abolished (Figures $4 \mathrm{~b}$ and c). Interestingly, even at high $\mathrm{Lu}$ gpFc concentrations in the ELISA the $\Delta 233-235$ mutation did not bind Ln511/521 (Figure 5b). These data are consistent with an essential role for the linker region in allowing D2 and D3, and the rest of the Lu gp molecule, to adopt a conformation capable of binding Ln511/521.

Taken in their entirety these mutagenesis data suggest the primary binding site for the Ln $\alpha 5$ chain is defined by negatively charged residues at the top of D3 and to a lesser extent at the base of D2. An appropriate presentation of both D2 and D3 for Ln511/521 binding is essential and appears to be dictated by the linker between these domains.

\section{Discussion}

Ln has previously been shown to bind to its other ligands (heparin, $\alpha$-dystroglycan) via positively charged basic residues on the LG domains adhering to areas of negative charge on its ligands ${ }^{21,22}$. The results presented here are consistent with a similar mechanism for the Ln $\alpha 5$ chain-Lu gp interaction. Inspection of the crystallographic structures of D1D2 and the model of D3 of Lu gp revealed dominant areas of negative electrostatic potential that we hypothesised form the Ln binding site. Many of the acidic residues in this region are conserved in the murine homologue that also binds to 
human Ln511/521 ${ }^{6}$. When negatively charged residues in the patch were mutated to alanine and the mutant proteins assessed for Ln511/521 binding by both ELISA and Biacore assay, residue D312 and, to a lesser extent, E309 and D310 were identified as critical residues. Other negatively charged residues in the vicinity of these three also had small effects on binding. When the positions of all the mutations made in this study are mapped to the crystallographic structure of D2 and the homology model of D3 those that affect the binding to Ln511/521 form a cluster at the domain interface (Figure 4), with the single exception of E180, the mutation of which caused an effect only in the surface plasmon resonance assay and not the ELISA. In the orientation of the D1D2D3 structure, along with the D1-D5 structure, shown in Figure 4 this cluster corresponds to a protrusion formed by the bend between D2 and D3, akin to a spur on the heel of a boot. We speculate that the negative charge on D312 interacts with a positively charged amino-acid on the $\operatorname{Ln} \alpha 5$ chain and that this charged interaction is the primary determinant of adhesion between the two molecules. The other acidic amino-acids identified here could potentially produce a localised negative charge on Lu gp around D312 and facilitate docking by interaction with other positive charges on the Ln $\alpha 5$ chain. The close homology between the sequence of human and murine Lu gp ${ }^{6}$ suggests that murine Lu gp has a similar structure to its human counterpart and binds Ln511/521 in an identical manner.

Our results demonstrate not only that the binding site for the Ln $\alpha 5$ chain is defined by negatively charged residues on D2 and D3 but also that the linker region between these domains is critical for binding. The approximately eight amino-acids that comprise the link between D2 and D3 are likely to have an open conformation as evidenced by the susceptibility of this region to proteolysis and by SAXS analysis that shows that the Lu gp structure is non-linear in this region. Unlike at the D1D2 junction, these residues are not predominantly hydrophobic (HYPTEHVQ) indicating the linker is unlikely to be buried within a tight interdomain interface. We have also shown that by placing a proline in this linker region $(\mathrm{H} 235 \mathrm{P})$ or by removing 3 amino-acids $(\Delta 233-235)$ and shortening the linker, $\mathrm{Lu}$ gp binding to Ln511/521 is totally abolished. These data could be interpreted as indicating residues T233, E234 and $\mathrm{H} 235$ are directly involved in binding to Ln511/521. However, this seems unlikely since mutation of E234A has only a minor effect on binding (Figure 3a and b). It is more plausible that in order to adhere to the $\mathrm{Ln} \alpha 5$ chain Lu gp D1D2 needs to be in a suitable spatial orientation relative to D3 and possibly also the stem formed by D4 and D5.

One interpretation of an extended conformation at the D2/D3 interface is that this region is likely to exhibit inter-domain flexibility. Although the crystal structures also show a degree of flexibility at the D1/D2 interface, the demonstration that domains 2 and 3 can readily fold when up to three amino-acids are removed from the linker region implies a more open association between these domains. This is reminiscent of the 4 domain tandem structure of $\mathrm{CD}^{48}$ where domains 1 and 2 are tightly associated, as are domains 3 and 4, whereas an extended linker at the domain 2/domain 3 interface leads to molecular flexibility at this junction. Similarly, CD2, which has a 4 amino-acid linker between IgSF domains 1 and 2, is also believed to undergo hinge bending shifts affecting domain orientation ${ }^{49}$ and exposing a buried antibody epitope during T-cell activation ${ }^{50}$. In Lu gp, it is unclear whether the potential flexibility this extended linker may generate is essential for Ln binding. Nonetheless, the demonstration that the binding site straddles the adjacent ends of D2 and D3 implies 
that only a discrete arrangement of the domains would form a coherent binding site; variations from this position would be expected to be deleterious for Ln binding. The assumption that the D2/D3 boundary is a source of flexibility therefore suggests an association between these movements and effective Ln binding. A precedent for this proposed mechanism is provided by the killer cell inhibitory receptors in which a linker region between two IgSF domains forms the MHC binding interface, with binding modulated by differences in the relative domain orientations ${ }^{51}$. The potential for domain-domain movement within $\mathrm{Lu}$ gp provides a possible explanation for the increase in adhesion to Ln511/521 observed in cells expressing Lu gp in response to 'inside-out' signalling events ${ }^{13-15}$.

A common feature of cell-cell adhesion pairs for which structures are available is the exploitation of the broad faces presented by amino-terminal IgSF domains (usually formed by the C'C'CFG sheet) to generate extensive contact surfaces ${ }^{52}$. These are typified in the CD2:CD58 pair $^{26}$ where some $1200 \AA^{2}$ of surface area are buried in a relatively flat interface within the complex. A recent exception is the SIRP $\alpha$ receptor which instead uses the complementarity-determining loop regions as the adhesion site, although these are at the amino terminal end of the receptor and assumed to be furthermost from the cell membrane ${ }^{52}$. Nonetheless, these and similar electrostatic interactions frequently generate only low-affinity binding. The Lu gp:Ln511/521 interaction differs substantially. The data presented here show this to be a highaffinity $\left(\mathrm{K}_{\mathrm{D}} \sim 10 \mathrm{nM}\right)$ interaction arising from a cluster of residues contributed from adjacent loop regions of two domains. It is feasible that enclosure of the ligand through domain movements may contribute to the slow off-rate of the complex. Indeed the $\mathrm{Lu}$ gp point mutations constructed in this study seemed only to have an effect on the on-rate of Ln binding and not the off rate (Figure 3d). Unlike many cell adhesion molecules, the binding surfaces in $\mathrm{Lu}$ gp are not located on the aminoterminal domain which would be most distal from the cell surface in the tandem arrangement implied by the overall shape of Lu gp (D1-D5). Access to the binding site would therefore either require interdigitation of extended $\mathrm{Ln}$ and $\mathrm{Lu}$ gp proteins when cells are located on the ECM or, alternatively, considerable flexing of Lu gp at the D2/D3 boundary in order to present the binding surface to the ligand. The extended structure observed for D1-D5 suggests that Lu gp does not adopt a compact structure akin to the horseshoe arrangement observed in both axonin ${ }^{53}$ and hemolin ${ }^{54}$ which could place the D2/D3 boundary furthermost from the cell surface. The predominance of sites for Lutheran blood group antigens on all faces of D1 and D2 (Figure 1c) also implies that these domains are fully exposed at the erythrocyte surface, again inconsistent with a compact structure. The angle generated by the D2D3 junction as described in this study may promote interactions between the D1D2 fragment and other ECM components. This angle is similar to that observed between the IgSF domains 2 and 3 of the neural cell adhesion molecule NCAM, for which a heparin binding site has also been located to domain $2^{55}$. There is currently no evidence, however, that Lu gp can undergo the zipper-like formation of homophilic interactions described for NCAM to build multi-molecular adhesion complexes.

Our findings provide clear evidence that $\mathrm{Lu}$ gp interaction with the $\mathrm{Ln} \alpha 5$ chain is mediated by a negatively charged patch on the tip of Lu gp extracellular D3 and base of D2 in a manner analogous to that occurring for the other ligands of Ln, heparin and $\alpha$-dystroglycan. In this case, the negatively charged patch is composed of glutamic and aspartic acid residues rather than sulphated sugars. Our results further suggest that 
the Ln511/521 binding site on Lu gp is located at a potentially flexible interdomain linker region and it is possible that the amino-terminal D1 and D2 may be required to fold back to expose the binding site for Ln511/521. Confirmation of this mechanism awaits further structural analysis of Lu gp and identification of the Lu gp binding site in the LG1-3 region of the Ln $\alpha 5$ chain. Nevertheless these findings pave the way for development of inhibitors of the Lu gp:Ln511/521 interaction and thereby potential novel therapies ameliorating vasocclusion in sickle cell disease.

\section{Acknowledgements}

We thank Dr Susan Ortlepp, CellTech Ltd., Slough, UK for expert help with Lu gp over-expression; Dr Becky Conners, University of Bristol, for assistance with X-ray data collection and advice; and Hugh Beedie and James Osborne (Information Services, Cardiff University) for implementation of distributed software through CONDOR. We are grateful to the staff at the Daresbury SRS and Hamburg DESY synchrotrons for support and access to these facilities

This work was supported in part by National Institutes of Health Grants DK56267 and DK32094; and by the Director, Office of Health and Environment Research Division, US Department of Energy, under Contract DE-AC03-76SF00098; and by the United Kingdom NHS R\&D Directorate. NB is supported by a studentship from the UK Medical Research Council.

Contribution: TJM and NB designed research, performed research, analyzed and interpreted data, drafted the manuscript; FOS, JSP CLPO, DL and TW performed research FAS drafted the manuscript; SFP performed research and drafted the manuscript; NM, JAC, RLB and DJA designed and directed research and drafted the manuscript.

This work was supported by the U.S. Department of Energy under Contract No. DE-AC02-05CH11231. 


\section{Reference List}

(1) Parsons SF, Mallinson G, Holmes $\mathrm{CH}$ et al. The Lutheran blood group glycoprotein, another member of the immunoglobulin superfamily, is widely expressed in human tissues and is developmentally regulated in human liver. Proc Natl Acad Sci U S A. 1995;92:5496-5500.

(2) Parsons SF, Mallinson G, Judson PA et al. Evidence that the $\mathrm{Lu}^{\mathrm{b}}$ blood group antigen is located on red cell membrane glycoproteins of 85 and $78 \mathrm{kd}$. Transfusion. 1987;27:61-63.

(3) Campbell IG, Foulkes WD, Senger G et al. Molecular cloning of the B-CAM cell surface glycoprotein of epithelial cancers: a novel member of the immunoglobulin superfamily. Cancer Res. 1994;54:5761-5765.

(4) Rahuel C, Le Van KC, Mattei MG, Cartron JP, Colin Y. A unique gene encodes spliceoforms of the B-cell adhesion molecule cell surface glycoprotein of epithelial cancer and of the Lutheran blood group glycoprotein. Blood. 1996;88:1865-1872.

(5) El Nemer W, Colin Y, Bauvy C et al. Isoforms of the Lutheran/basal cell adhesion molecule glycoprotein are differentially delivered in polarized epithelial cells. Mapping of the basolateral sorting signal to a cytoplasmic dileucine motif. J Biol Chem. 1999;274:31903-31908.

(6) Parsons SF, Lee G, Spring FA et al. Lutheran blood group glycoprotein and its newly characterized mouse homologue specifically bind alpha5 chaincontaining human laminin with high affinity. Blood. 2001;97:312-320.

(7) Moulson CL, Li C, Miner JH. Localization of Lutheran, a novel laminin receptor, in normal, knockout, and transgenic mice suggests an interaction with laminin alpha5 in vivo. Dev Dyn. 2001;222:101-114.

(8) El Nemer W, Gane P, Colin Y et al. The Lutheran blood group glycoproteins, the erythroid receptors for laminin, are adhesion molecules. J Biol Chem. 1998;273:16686-16693.

(9) Udani M, Zen Q, Cottman M et al. Basal cell adhesion molecule/lutheran protein. The receptor critical for sickle cell adhesion to laminin. J Clin Invest. 1998;101:2550-2558.

(10) Aumailley M, Bruckner-Tuderman L, Carter WG et al. A simplified laminin nomenclature. Matrix Biol. 2005;24:326-332.

(11) Lee SP, Cunningham ML, Hines PC et al. Sickle cell adhesion to laminin: potential role for the alpha5 chain. Blood. 1998;92:2951-2958.

(12) Parsons SF, Spring FA, Chasis JA, Anstee DJ. Erythroid cell adhesion molecules Lutheran and LW in health and disease. Baillieres Best Pract Res Clin Haematol. 1999;12:729-745. 
(13) Hines PC, Zen Q, Burney SN et al. Novel epinephrine and cyclic AMPmediated activation of BCAM/Lu-dependent sickle (SS) RBC adhesion. Blood. 2003;101:3281-3287.

(14) Murphy MM, Zayed MA, Evans A et al. Role of Rap1 in promoting sickle red blood cell adhesion to laminin via BCAM/LU. Blood. 2005;105:3322-3329.

(15) Gauthier E, Rahuel C, Wautier MP et al. Protein kinase A-dependent phosphorylation of Lutheran/basal cell adhesion molecule glycoprotein regulates cell adhesion to laminin alpha5. J Biol Chem. 2005;280:3005530062 .

(16) El Nemer W, Gane P, Colin Y et al. Characterization of the laminin binding domains of the Lutheran blood group glycoprotein. J Biol Chem. 2001;276:23757-23762.

(17) Kikkawa Y, Moulson CL, Virtanen I, Miner JH. Identification of the binding site for the Lutheran blood group glycoprotein on laminin alpha 5 through expression of chimeric laminin chains in vivo. J Biol Chem. 2002;277:4486444869.

(18) Kikkawa Y, Sasaki T, Nguyen MT et al. The LG1-3 Tandem of Laminin $\alpha 5$ Harbors the Binding Sites of Lutheran/Basal Cell Adhesion Molecule and $\alpha 3 \beta 1 / \alpha 6 \beta 1$ Integrins. J Biol Chem. 2007;282:14853-14860.

(19) $\mathrm{Yu} \mathrm{H}$, Talts JF. Beta1 integrin and alpha-dystroglycan binding sites are localized to different laminin-G-domain-like (LG) modules within the laminin alpha5 chain G domain. Biochem J. 2003;371:289-299.

(20) Ido H, Harada K, Futaki S et al. Molecular dissection of the alphadystroglycan- and integrin-binding sites within the globular domain of human laminin-10. J Biol Chem. 2004;279:10946-10954.

(21) Andac Z, Sasaki T, Mann K et al. Analysis of heparin, alpha-dystroglycan and sulfatide binding to the $\mathrm{G}$ domain of the laminin alphal chain by site-directed mutagenesis. J Mol Biol. 1999;287:253-264.

(22) Hohenester E, Tisi D, Talts JF, Timpl R. The crystal structure of a laminin Glike module reveals the molecular basis of alpha-dystroglycan binding to laminins, perlecan, and agrin. Mol Cell. 1999;4:783-792.

(23) Talts JF, Andac Z, Gohring W, Brancaccio A, Timpl R. Binding of the G domains of laminin alpha1 and alpha 2 chains and perlecan to heparin, sulfatides, alpha-dystroglycan and several extracellular matrix proteins. EMBO J. 1999;18:863-870.

(24) Wizemann H, Garbe JH, Friedrich MV et al. Distinct requirements for heparin and alpha-dystroglycan binding revealed by structure-based mutagenesis of the laminin alpha2 LG4-LG5 domain pair. J Mol Biol. 2003;332:635-642. 
(25) Michele DE, Campbell KP. Dystrophin-glycoprotein complex: posttranslational processing and dystroglycan function. J Biol Chem. 2003;278:15457-15460.

(26) Wang JH, Smolyar A, Tan K et al. Structure of a heterophilic adhesion complex between the human CD2 and CD58 (LFA-3) counterreceptors. Cell. 1999;97:791-803.

(27) Evans EJ, Castro MA, O'Brien R et al. Crystal structure and binding properties of the CD2 and CD244 (2B4)-binding protein, CD48. J Biol Chem. 2006;281:29309-29320.

(28) Dando J, Wilkinson KW, Ortlepp S, King DJ, Brady RL. A reassessment of the MAdCAM-1 structure and its role in integrin recognition. Acta Crystallogr D Biol Crystallogr. 2002;58:233-241.

(29) Schneider TR, Sheldrick GM. Substructure solution with SHELXD. Acta Crystallogr D Biol Crystallogr. 2002;58:1772-1779.

(30) CCP4. The CCP4 suite: programs for protein crystallography. Acta Crystallogr D Biol Crystallogr. 1994;50:760-763.

(31) Perrakis A, Morris R, Lamzin VS. Automated protein model building combined with iterative structure refinement. Nat Struct Biol. 1999;6:458-463.

(32) McCoy AJ, Grosse-Kunstleve RW, Storoni LC, Read RJ. Likelihoodenhanced fast translation functions. Acta Crystallogr D Biol Crystallogr. 2005;61:458-464.

(33) Brunger AT, Adams PD, Clore GM et al. Crystallography \& NMR system: A new software suite for macromolecular structure determination. Acta Crystallogr D Biol Crystallogr. 1998;54:905-921.

(34) Davis IW, Murray LW, Richardson JS, Richardson DC. MOLPROBITY: structure validation and all-atom contact analysis for nucleic acids and their complexes. Nucleic Acids Res. 2004;32:W615-W619.

(35) Kvansakul M, Hopf M, Ries A, Timpl R, Hohenester E. Structural basis for the high-affinity interaction of nidogen-1 with immunoglobulin-like domain 3 of perlecan. EMBO J. 2001;20:5342-5346.

(36) Cuff JA, Barton GJ. Evaluation and improvement of multiple sequence methods for protein secondary structure prediction. Proteins. 1999;34:508519.

(37) Cuff JA, Clamp ME, Siddiqui AS, Finlay M, Barton GJ. JPred: a consensus secondary structure prediction server. Bioinformatics. 1998;14:892-893.

(38) Karplus K, Karchin R, Draper J et al. Combining local-structure, foldrecognition, and new fold methods for protein structure prediction. Proteins. 2003;53 Suppl 6:491-496. 
(39) Marti-Renom MA, Stuart AC, Fiser A et al. Comparative protein structure modeling of genes and genomes. Annu Rev Biophys Biomol Struct. 2000;29:291-325.

(40) Baldock C, Siegler V, Bax DV et al. Nanostructure of fibrillin-1 reveals compact conformation of EGF arrays and mechanism for extensibility. Proc Natl Acad Sci U S A. 2006;103:11922-11927.

(41) Pedersen JS. A flux- and background-optimized version of the NanoSTAR small-angle X-ray scattering camera for solution scattering. J Appl Cryst. 2004;37:369-378.

(42) Parsons SF, Mallinson G, Daniels GL et al. Use of domain-deletion mutants to locate Lutheran blood group antigens to each of the five immunoglobulin superfamily domains of the Lutheran glycoprotein: elucidation of the molecular basis of the $\mathrm{Lu}(\mathrm{a}) / \mathrm{Lu}(\mathrm{b})$ and the $\mathrm{Au}(\mathrm{a}) / \mathrm{Au}(\mathrm{b})$ polymorphisms. Blood. 1997;89:4219-4225.

(43) Mankelow TJ, Spring FA, Parsons SF et al. Identification of critical aminoacid residues on the erythroid intercellular adhesion molecule-4 (ICAM-4) mediating adhesion to alpha V integrins. Blood. 2004;103:1503-1508.

(44) Crew VK, Green C, Daniels G. Molecular bases of the antigens of the Lutheran blood group system. Transfusion. 2003;43:1729-1737.

(45) Svergun DI. Restoring low resolution structure of biological macromolecules from solution scattering using simulated annealing. Biophys J. 1999;76:28792886.

(46) Svergun DI, Petoukhov MV, Koch MH. Determination of domain structure of proteins from X-ray solution scattering. Biophys J. 2001;80:2946-2953.

(47) Petoukhov MV, Svergun DI. Global rigid body modeling of macromolecular complexes against small-angle scattering data. Biophys J. 2005;89:1237-1250.

(48) Wu H, Kwong PD, Hendrickson WA. Dimeric association and segmental variability in the structure of human CD4. Nature. 1997;387:527-530.

(49) Jones EY, Davis SJ, Williams AF, Harlos K, Stuart DI. Crystal structure at 2.8 A resolution of a soluble form of the cell adhesion molecule CD2. Nature. 1992;360:232-239.

(50) Li J, Smolyar A, Sunder-Plassmann R, Reinherz EL. Ligand-induced conformational change within the CD2 ectodomain accompanies receptor clustering: implication for molecular lattice formation. J Mol Biol. 1996;263:209-226.

(51) Maenaka K, Juji T, Stuart DI, Jones EY. Crystal structure of the human p58 killer cell inhibitory receptor (KIR2DL3) specific for HLA-Cw3-related MHC class I. Structure. 1999;7:391-398. 
(52) Hatherley D, Harlos K, Dunlop DC, Stuart DI, Barclay AN. The structure of the macrophage SIRPalpha inhibitory receptor reveals a binding face reminiscent of that used by T cell receptors. J Biol Chem. 2007;282:1456714575 .

(53) Freigang J, Proba K, Leder L et al. The crystal structure of the ligand binding module of axonin-1/TAG-1 suggests a zipper mechanism for neural cell adhesion. Cell. 2000;101:425-433.

(54) Su XD, Gastinel LN, Vaughn DE et al. Crystal structure of hemolin: a horseshoe shape with implications for homophilic adhesion. Science. 1998;281:991-995.

(55) Soroka V, Kolkova K, Kastrup JS et al. Structure and interactions of NCAM Ig1-2-3 suggest a novel zipper mechanism for homophilic adhesion. Structure. 2003;11:1291-1301. 
Table 1

\begin{tabular}{|c|c|c|c|c|c|c|}
\hline & $\begin{array}{l}\text { Hexagonal } \\
\text { Native }\end{array}$ & $\begin{array}{l}\text { Monoclinic } \\
\text { Native }\end{array}$ & $\begin{array}{l}\text { Au } \\
\text { derivative, } \\
\text { high } \\
\text { energy } \\
\text { remote }\end{array}$ & $\begin{array}{l}\text { Au } \\
\text { derivative, } \\
\text { low energy } \\
\text { remote }\end{array}$ & $\begin{array}{l}\text { Pt } \\
\text { derivative, } \\
\text { high } \\
\text { energy } \\
\text { remote }\end{array}$ & $\begin{array}{l}\text { Pt } \\
\text { derivative, } \\
\text { low energy } \\
\text { remote }\end{array}$ \\
\hline Wavelength $(\AA)$ & 1.488 & 1.285 & 1.01 & 1.042 & 1.071 & 1.08 \\
\hline Spacegroup & $\mathrm{P} 3{ }_{2} 21$ & $\mathrm{P} 2_{1}$ & $\mathrm{P} 2_{1}$ & $\mathrm{P} 2_{1}$ & $\mathrm{P} 2_{1}$ & $\mathrm{P} 2_{1}$ \\
\hline $\begin{array}{l}\text { Resolution range } \\
(\AA)\end{array}$ & $\begin{array}{l}44.6-2.2 \\
(2.28-2.2)\end{array}$ & $\begin{array}{l}35.3-1.7 \\
(1.76-1.7)\end{array}$ & $\begin{array}{l}35.7-1.8 \\
(1.86-1.8)\end{array}$ & $\begin{array}{l}35.7-1.8 \\
(1.86-1.8)\end{array}$ & $\begin{array}{l}36.1-2.5 \\
(2.59-2.5)\end{array}$ & $\begin{array}{l}33.5-2.5 \\
(2.59-2.5)\end{array}$ \\
\hline Redundancy & $5.6(1.8)$ & $6.4(2.0)$ & $8.6(2.7)$ & $8.9(3.3)$ & $6.8(3.0)$ & $5.9(1.8)$ \\
\hline Completeness & $90.1(41.3)$ & $89.1(48.3)$ & $89.5(50.3)$ & $90.5(49.6)$ & $93.6(70.3)$ & $85.4(32.6)$ \\
\hline Rmerge & $10.2(48.2)$ & $5.9(26.4)$ & $9.8(23.3)$ & $6.9(20.0)$ & $11.8(26.3))$ & $8.9(32.6$ \\
\hline $\mathrm{I} /$ sigl & $14.1(1.2)$ & $26.5(2.5)$ & $19.7(2.8)$ & $29.2(3.7)$ & $16.5(1.1)$ & $15.9(2.6)$ \\
\hline $\begin{array}{l}\text { Isomorphous } \\
\text { Rcullis } \\
\text { (acentrics/centrics) }\end{array}$ & & & $0.51 / 0.65$ & $0.52 / 0.67$ & $0.85 / 0.91$ & $0.87 / 0.92$ \\
\hline Anomalous Rcullis & & & 0.83 & 0.88 & 0.95 & 0.97 \\
\hline $\begin{array}{l}\text { Initial Phase } \\
\text { Figure-of-Merit }\end{array}$ & & 0.73 & & & & \\
\hline Unique reflections & 18741 & 23563 & & & & \\
\hline Rwork & 0.205 & 0.168 & & & & \\
\hline Rfree & 0.251 & 0.21 & & & & \\
\hline Non-H atoms & 3643 & 2096 & & & & \\
\hline $\begin{array}{l}\text { Bond Length } \\
\text { RMSD (Å) }\end{array}$ & 0.018 & 0.015 & & & & \\
\hline $\begin{array}{l}\text { Bond Angle RMSD } \\
\text { ( })\end{array}$ & 1.498 & 1.678 & & & & \\
\hline
\end{tabular}

Table 1: Diffraction data processing and refinement statistics for D1D2 crystal forms. Values in parentheses refer to the highest resolution shell. 


\section{Figure Legends}

Figure 1. Structure of Lu gp D1D2. (a) Cartoon representation in stereo showing the Lu gp structure. D1 is shown at the top and D2 at the bottom. The strands in each domain are labelled, as are the amino $(\mathrm{N})$ and carboxy termini (C). (b) Overlay of $\mathrm{C} \alpha$ traces from the three independent copies of D1D2 in the two crystal structures. Orientation is as in (a). (c) Location of residues that are altered in the known inherited forms of $\mathrm{Lu}$ gp that can be attributed to D1D2. Mutated residues are shown in stick form, and are coloured as follows: Lu a/b - red, Lu4 - purple, Lu5 - yellow, Lu8/14 blue, Lu12 - pink, Lu16 - grey and Lu17 - orange.

Figure 2. SAXS analysis of Lu gp D1D2D3. (a) Experimental scattering data for Lu gp D1D2D3 plotted in black as a function of $\mathrm{q}$ and compared with a theoretical fit generated with SASREF ${ }^{47}$. (b) Shapes obtained using a bead model using the program $\mathrm{GASBOR}^{46}$ from 20 independent simulations, each differently coloured. The average shape is shown as orange wire-frame density in: (c) Representative rigid-body fit of the D1D2 crystal structure and D3 model to the scattering data, overlaid on average density obtained as in (b). D1 is shown in blue, D2 in green and D3 in red. (d) Shapes obtained from the scattering curve for Lu gp (D1-D5) as described in (b). The average shape is shown as orange wire-frame density in: (e) Overlay of the D1D2D3 model on the envelope derived for Lu gp (D1-D5). D4 and D5 are expected to occupy the additional density at the base of the figure, proximal to the cell membrane.

Figure 3. Mutation of acidic residues of Lu gp reduces Ln511/521 binding. (a) Representative ELISA titrations of 5, 0.5, 0.05 and $0.005 \mathrm{nM} \mathrm{Lu}$ gp binding to $5 \mathrm{nM}$ Ln511/521 for the E309A, D310A, D312A and D315A (solid line) mutations in comparison to native Lu gp (dashed line). Standard deviation for each point is under 0.1. ELISA results of all other mutations can be seen in Supplementary Data 4. (b) The level of binding to Ln511/521 of mutant Lu gp compared with the native protein at $0.05 \mathrm{nM}$ measured in an ELISA. Proteins were assayed in duplicate and the results shown are the mean of two separate ELISA plates and are expressed as the percentage of the absorption seen from wells containing native $\mathrm{Lu}$ gpFc $\left(\mathrm{OD}_{450}=0.95\right)$. (c) Ln511/521 binding assessed by surface plasmon resonance using a BiacoreX. Shown is the mean change in response units (RU) over the course of a $100 \mu$ injection of 10nM Ln511/521 for two assays per protein. In both (b) and (c) Ln511/521 binding to Muc18 acted as a negative control. (d) Overlaid sensorgrams for a representative sample of the different proteins showing the association and dissociation curves of Ln511/521 binding to Lu gpFc. Vertical arrows indicate the beginning and end points of the Ln511/521 injection.

Figure 4. Location of charged amino-acid residues involved in interactions with Ln511/521 on the surface of Lu gp. (a) Lu gp domains D1D2 (dark grey) and D3 (light grey) are shown in an orientation consistent with the SAXS envelope. Indicated are the positions of acidic residues that have been mutated to alanine. The residues are colour coded according to their effect on Ln511/521 binding; Blue - No effect, Yellow - slight effect, Orange - marked effect and Red - severe effect. (b) Lu D1D2D3 in the same orientation, shown as an electrostatic surface.

Figure 5. Ln511/521 binding to D2-D3 linker mutants. 
(a) Three proteins, T233P, H235P and $\Delta 233-235$ (darker shade), containing mutations within the domain 2 to 3 hinge were made. (b) Representative ELISA titration's of hinge region mutants to Ln511/521 in comparison to binding to the native protein. Standard deviations were less than 0.1 OD units for any point. (c) The sensorgrams of representative Biacore assays with these mutants are shown. 
Figure 1

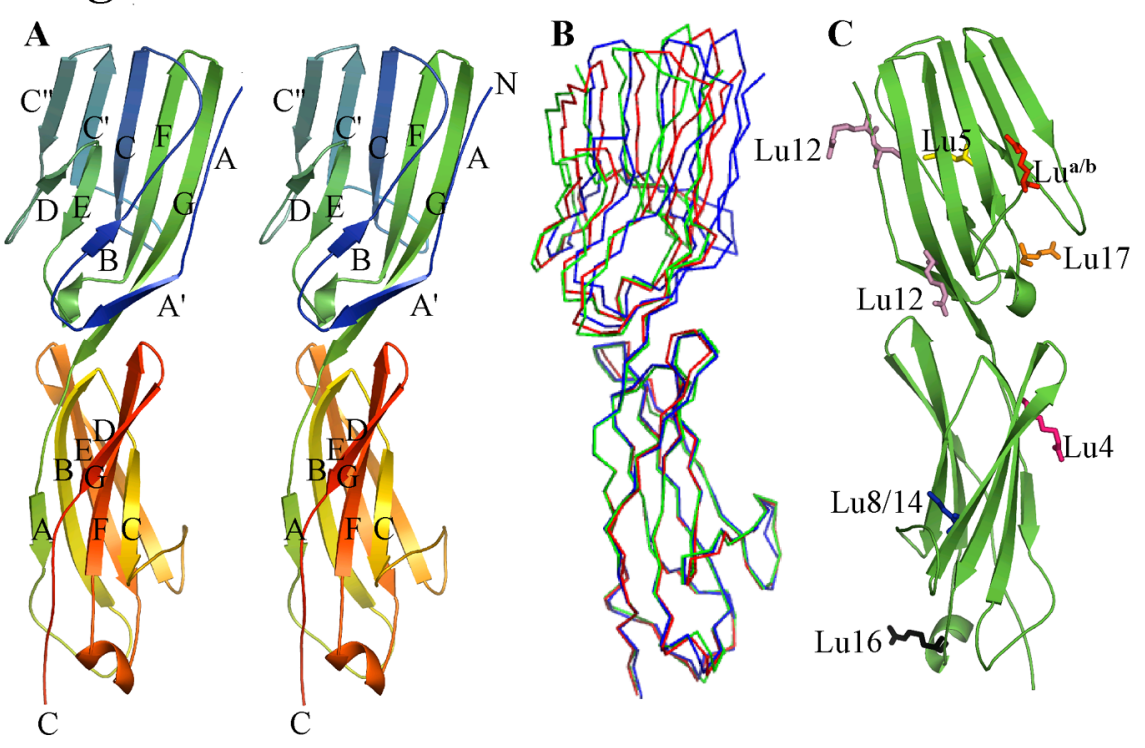


A $\quad$ Figure 2
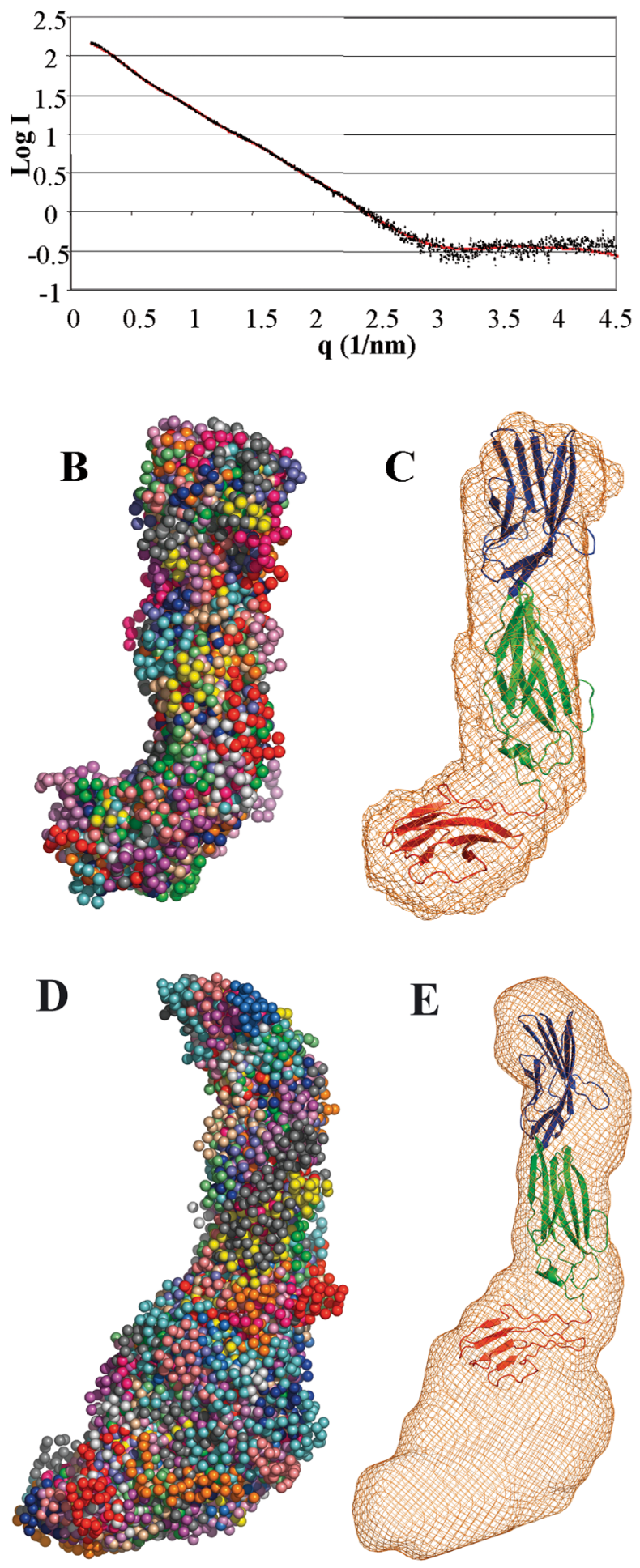


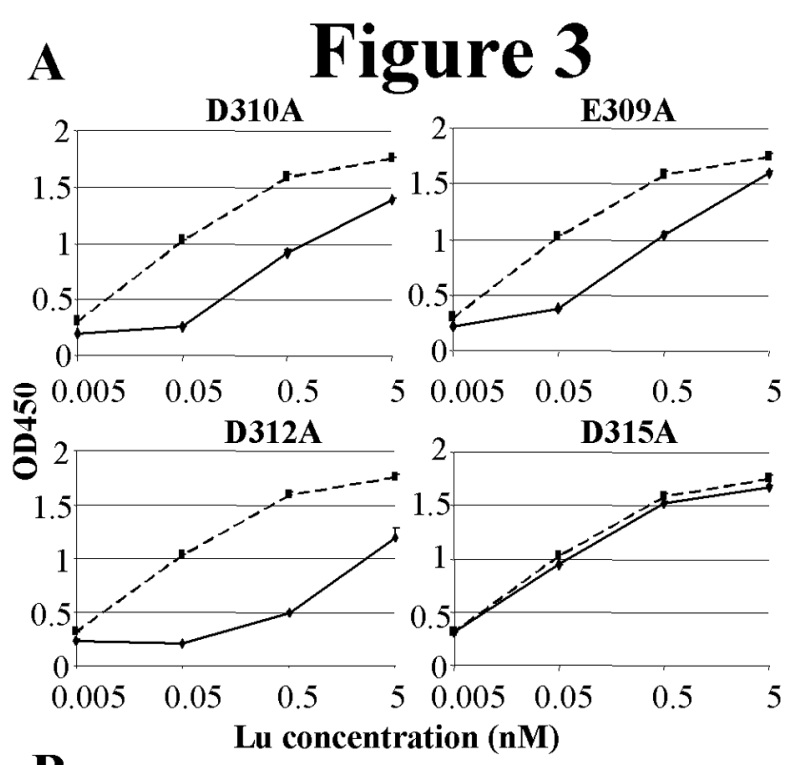

B
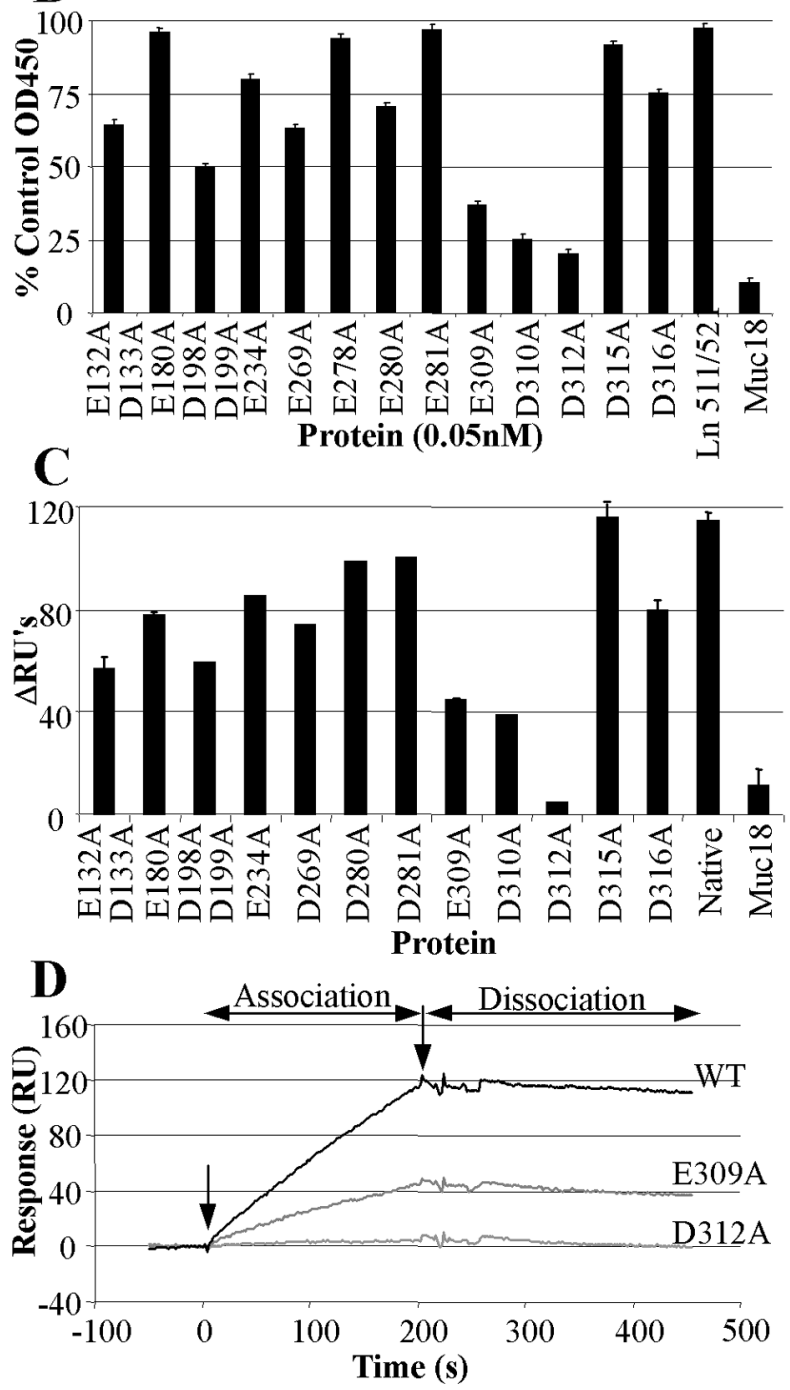
Figure 4
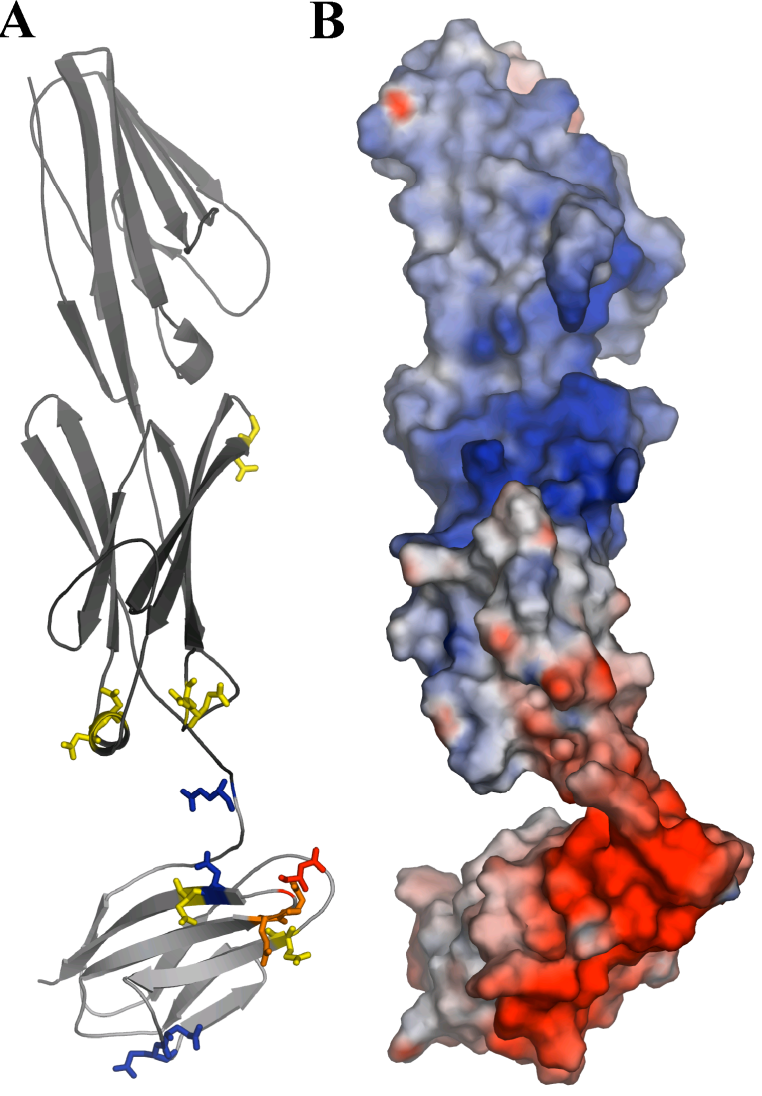


\section{Figure 5}

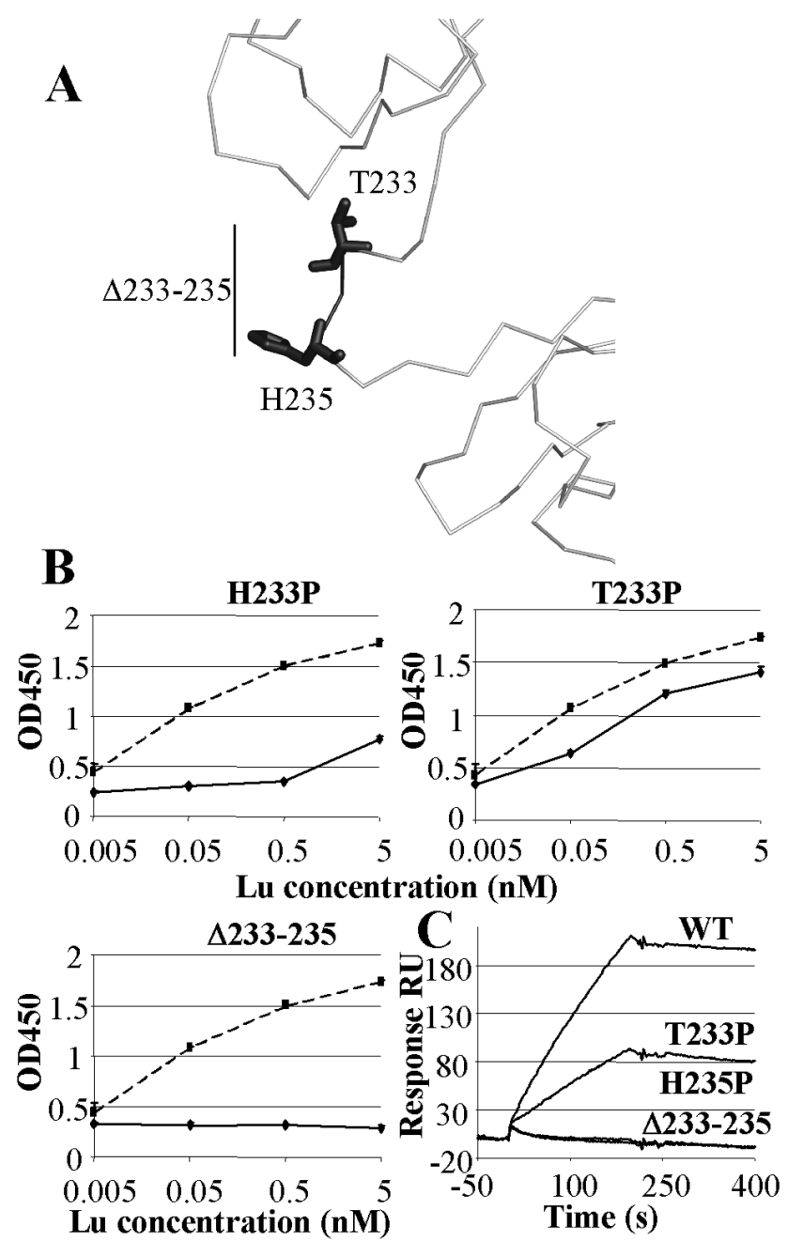




\section{Supplementary Data 1}

\section{Small-Angle X-ray scattering analysis - Full method}

SAXS data of D1D2D3 were collected on beamline X33 at the European Molecular Biology Laboratory (EMBL) of the Deutsches Elektronen Synchrotron (DESY) using a wavelength of $\lambda=0.15 \mathrm{~nm}$. The sample to detector distance was $2.4 \mathrm{~m}$, covering a scattering range of $0.16 \mathrm{~nm}^{-1}<\mathrm{q}<4.85 \mathrm{~nm}^{-1}$. The modulus of the scattering vector is defined as $q=4 \pi \sin \theta / \lambda$, where $2 \theta$ is the scattering vector. SAXS data were collected from D1D2D3 at concentrations of $4.375 \mathrm{mg} / \mathrm{ml}, 8.75 \mathrm{mg} / \mathrm{ml}$ and $17.5 \mathrm{mg} / \mathrm{ml}$; samples were exposed for $60 \mathrm{~s} .1 \mathrm{mM}$ dithiothreitol was added to each concentration of D1D2D3 solution before data collection to minimise aggregation. The scattering images were integrated to one-dimensional linear profiles using in-house software at station X33. Scattering data from the corresponding buffer were collected and subtracted from the sample data in order to remove background scattering. This was achieved using PRIMUS ${ }^{1}$. The corrected data at each concentration were then merged together using PRIMUS. GNOM, the indirect Fourier transform program ${ }^{2}$ was then applied to evaluate the particle distance distribution function, $\mathrm{p}(\mathrm{r})$, and the radius of gyration, $\mathrm{Rg}$. The shape of the protein was evaluated from the scattering data using the programs DAMMIN ${ }^{3}$ and GASBOR $^{4}$, which are applications that use ab initio procedures to build models of proteins using simulated annealing. Twenty simulations were performed with each program, and the structures generated were averaged using DAMAVER $^{5}$. Rigid-body modelling used the three unique crystallographically determined structures of D1D2, the D3 homology model and carbohydrate fragments extracted from PDB 1L6X. These were fitted to the scattering data with the program SASREF $^{6}$, theoretical scattering curves for each rigid body being computed with CRYSOL ${ }^{7}$.

SAXS measurements of the entire extracellular portion of Lu (D1-D5) were obtained on a modified version of the commercially available NanoSTAR (Bruker AXS, Karlsruhe) X-ray facility at the University of Aarhus. Further details about the modified NanoSTAR are given in $^{8}$. Data were collected at a concentration of 15 $\mathrm{mg} / \mathrm{ml}$, and were exposed for 1 hour. Data collection was conducted at $4{ }^{\circ} \mathrm{C}$ in a reusable thermostated quartz capillary, which is mounted in an in-house built capillary holder with good thermal contact to the thermostated surrounding block. The capillary holder was then positioned in the vacuum chamber. The sample to detector distance was $65 \mathrm{~cm}$, covering a scattering range of $0.085<\mathrm{q}<3.5 \mathrm{~nm}^{-1}$. The scattering data were corrected for variations in detector efficiency and spatial distortions. The twodimensional data were azimuthally averaged to one-dimensional linear profiles using Bruker SAXS software for Windows ${ }^{\mathrm{TM}}$ NT. Using in-house software at the University of Aarhus, the scattering data from the corresponding buffer were subtracted from the sample data, and the scattering intensities were transformed to absolute units using the scattering of water as a standard. Ab initio shape reconstruction was performed as described above for the D1D2D3 construct.

\section{Reference List}

(1) Konarev PV, Volkov VV, Sokolova AV, Koch MHJ, Svergun DI. PRIMUS: a Windows PC-based system for small-angle scattering data analysis. Journal of Applied Crystallography. 2003;36:1277-1282. 
(2) Semenyuk AV, Svergun DI. GNOM - a program package for small-angle scattering data processing. J Appl Cryst. 1991;24:537-540.

(3) Svergun DI. Restoring low resolution structure of biological macromolecules from solution scattering using simulated annealing. Biophys J. 1999;76:28792886.

(4) Svergun DI, Petoukhov MV, Koch MH. Determination of domain structure of proteins from X-ray solution scattering. Biophys J. 2001;80:2946-2953.

(5) Volkov VV, Svergun DI. Uniqueness of ab initio shape determination in smallangle scattering. J Appl Cryst. 2003;36:860-864.

(6) Petoukhov MV, Svergun DI. Global rigid body modeling of macromolecular complexes against small-angle scattering data. Biophys J. 2005;89:1237-1250.

(7) Svergun DI, Barberato C, Koch MHJ. CRYSOL - a Program to Evaluate X-ray Solution Scattering of Biological Macromolecules from Atomic Coordinates. Journal of Applied Crystallography. 1995;28:768-773.

(8) Pedersen JS. A flux- and background-optimized version of the NanoSTAR small-angle X-ray scattering camera for solution scattering. J Appl Cryst. 2004;37:369-378.

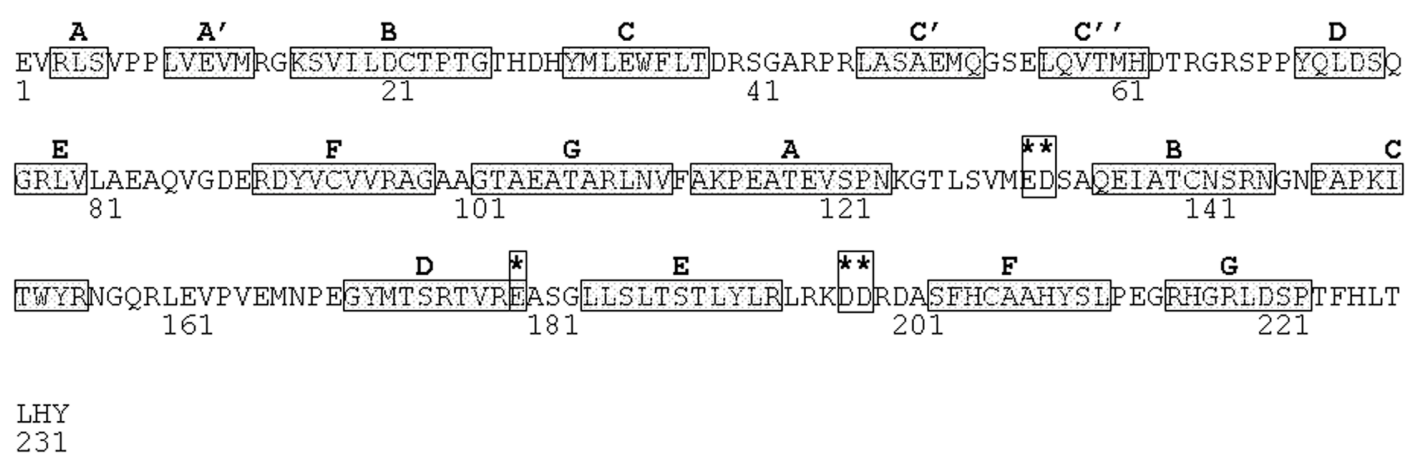

Supplementary Data 2 Sequence of Lu gp D1D2. The $\beta$-strands observed in the crystal structure are indicated by shaded boxes and labeled with bold letters. Mutated residues that affect binding are indicated with boxes and labeled with asterisks. 
$\mathbf{A}$

i ii iii iv $\mathrm{v}$ vi vii viii $\mathrm{ix} \quad \mathrm{x} \quad \mathrm{xi}$ xii xiii

203

130

94

48.6
B

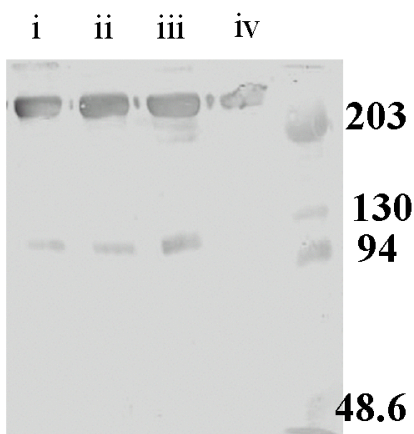

Supplementary Data 3 Western blots using Bric 224 (a) followed by a rabbit antimouse HRP secondary Ab was performed on non-reduced samples $(0.2 \mu \mathrm{gs})$ and using a anti human Fc HRP conjugate. Lanes are i-E132A/D133A, ii-E180A, iiiD198A/D199A, iv E234A, v-D269A, vi-D280A, vii-D281A, viii- E309A, ix- E310A, x- D312A, xi- D315A, xii- D316A and xiii- Native Lu. Non- reduced Western blots using Bric 224 (b) of $\Delta 233-235$ (i), T233P (ii) H235P (iii), linker mutations and native Lu (iv) are shown. 

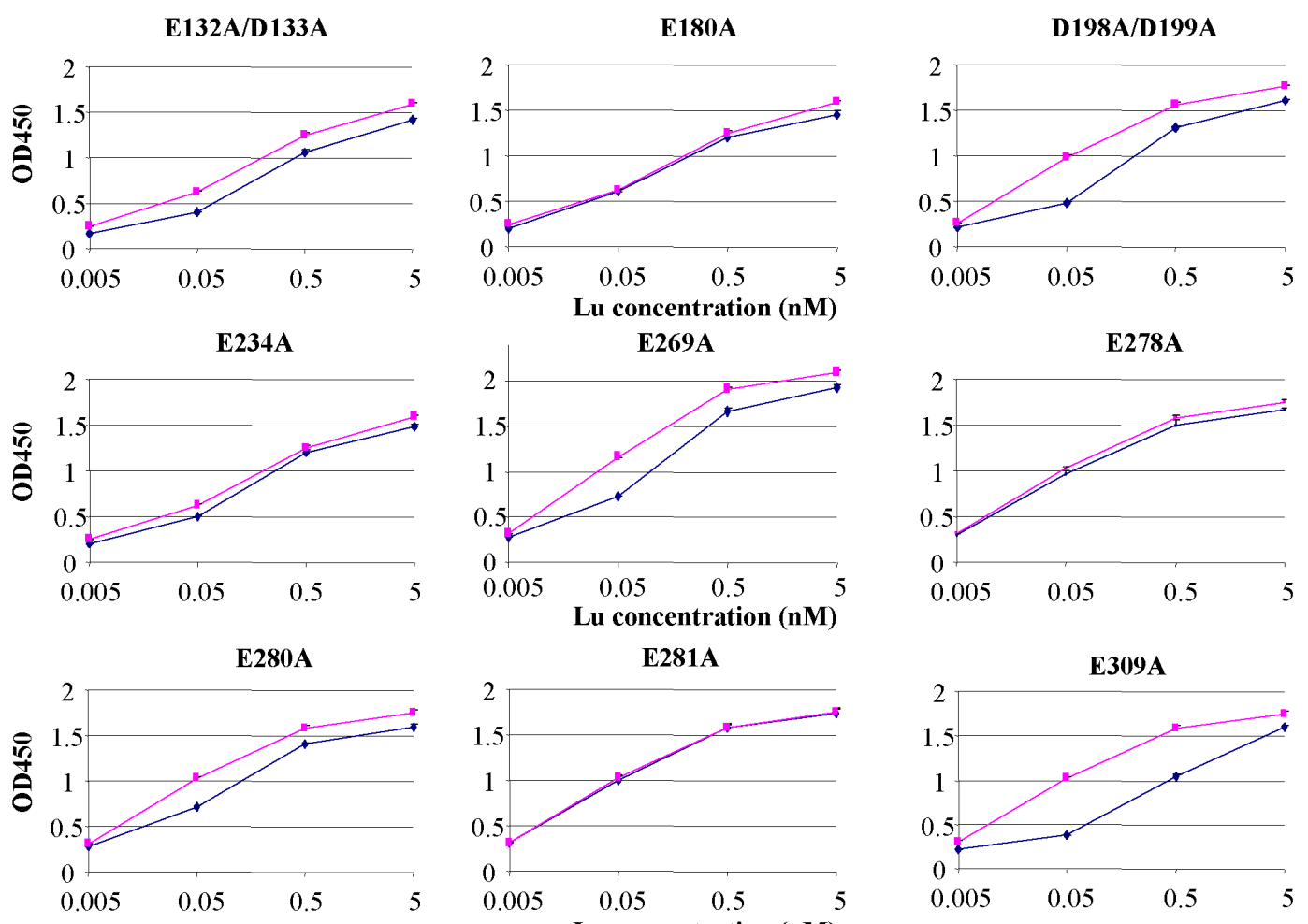

E281A
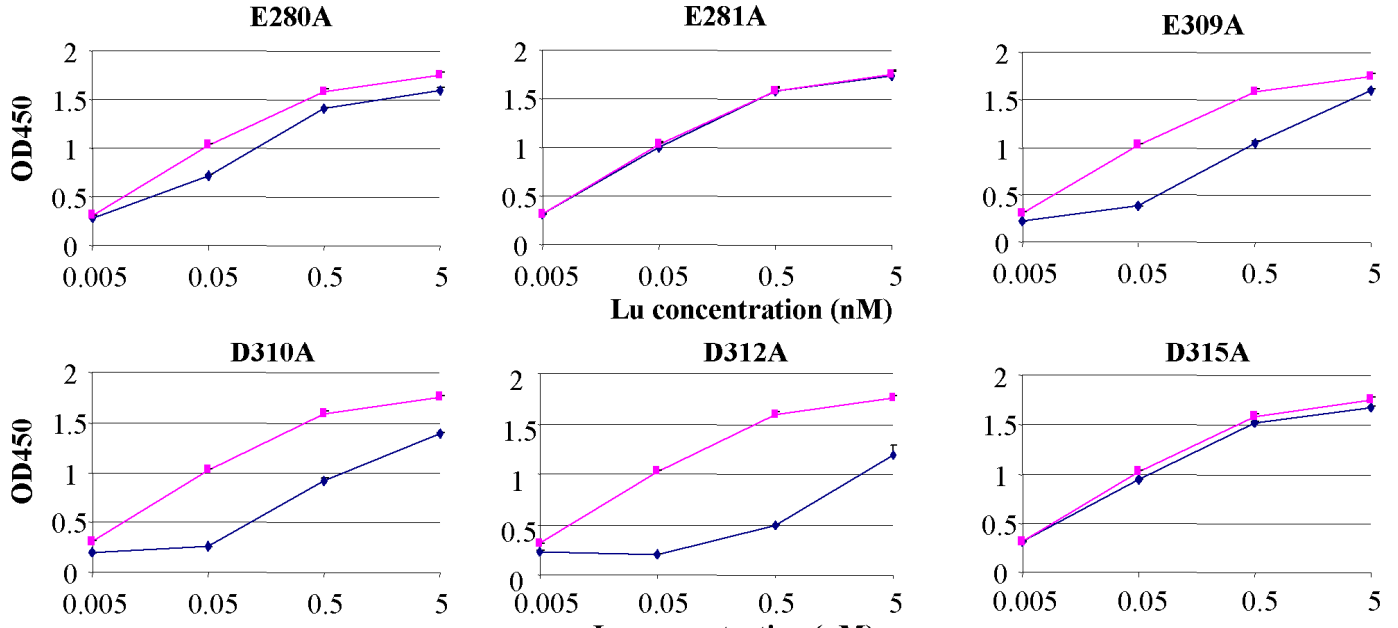

D312A
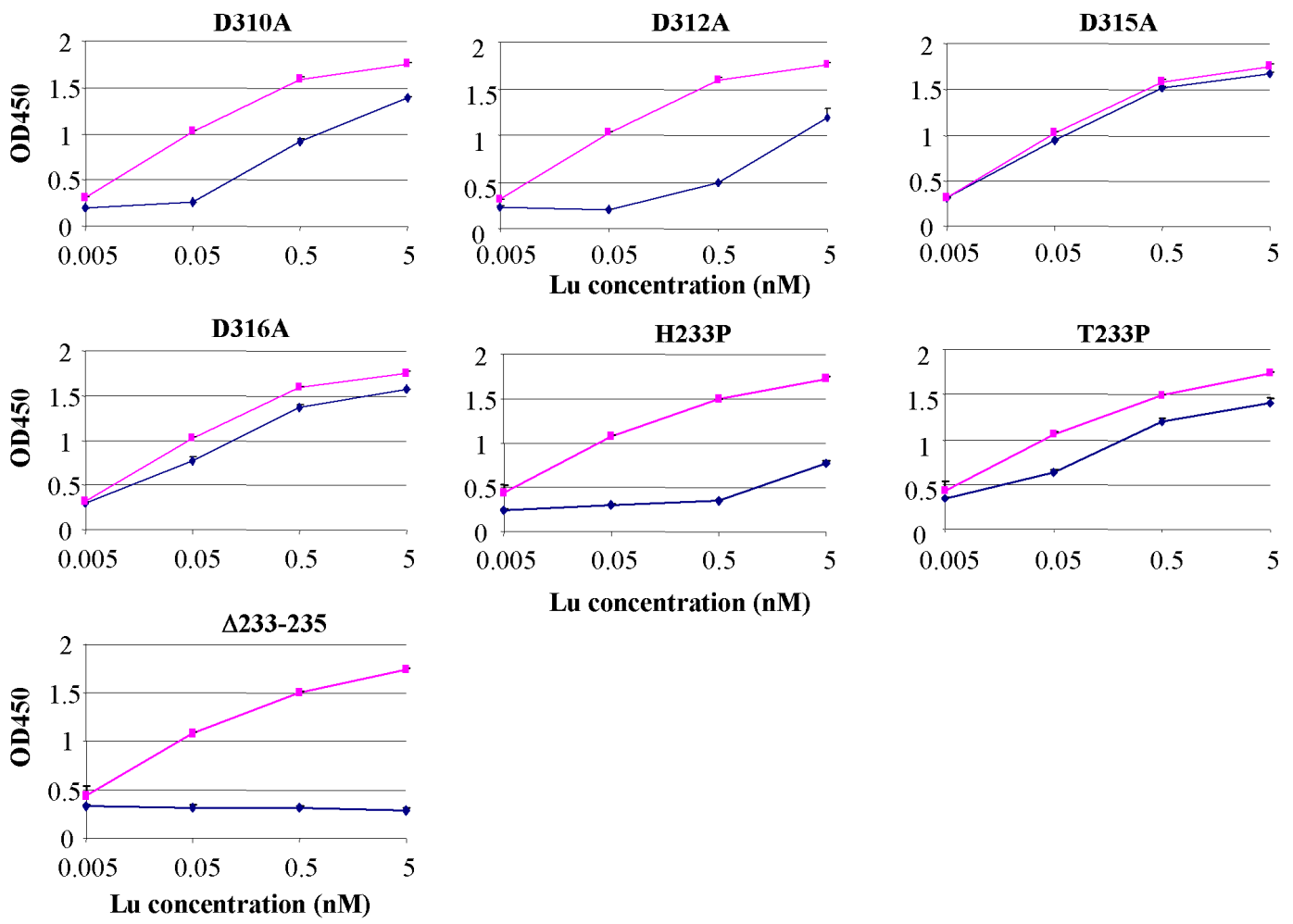

\section{Supplementary Data 4}

Representative ELISA titration's of 5, 0.5, 0.05 and $0.005 \mathrm{nM} \mathrm{Lu}$ gp binding to $5 \mathrm{nM}$ Ln511/521 for the Mutated Lu gpFc (Blue) mutations in comparison to native Lu gp (Magenta). Standard deviation for each point is under 0.1. 